\title{
The impact of heuristics and biases in the application of professional judgment by internal auditors in the stage of fieldwork
}

\author{
Jonathan Tanone \& Senny Harindahyani \\ University of Surabaya, Surabaya, Indonesia
}

\begin{abstract}
This study aims to find the impact of heuristics and bias in the application of professional judgment by internal auditors in the stage of fieldwork in "Company X", a company engaged in the distribution of fuel oil in West Nusa Tenggara. "Company X" has conducted internal audit activities although the effort is not maximized. This research was conducted by using the qualitative approach with an interpretive paradigm to explain these anomalies within internal auditor's professional judgment. The internal audit activities within "Company X" have some hindrance to the heuristic thinking process of the audit team members. One of them is a bias which caused interference within the audit team member heuristic. There are some forms of bias in audit namely overconfidence, availability, confirmation, and anchoring. All of them affect "Company X" internal auditor's professional judgment significantly except availability bias.
\end{abstract}

Keywords: heuristics, bias, internal audit, professional judgment.

\section{INTRODUCTION}

A proper internal audit should give a company an insight about how the company performs throughout the year. However, the implementation of internal audit requires an independence and objectivity from the auditor to make necessary or to take a proper judgment. In making such decision through professional judgment, the auditor must consider and analyze every data that have been gathered. There's an interesting term regarding human's information processing aspect, namely Social Cognition. Social Cognition illustrates how a person thinks about their social world around them (Fiske \& Taylor 2008). Social Cognition itself has several forms, but in this study, we discussed more about dual processing theory, heuristics within those systems, and also about biases that affects heuristics inside the processing system towards the professional judgment of internal auditors. Heuristics and biases are 2 subjects that can't be separated. Heuristics is likened as a strategy to speed up processing to make a decision, and bias itself is likened to be an unexpected factor that can disrupt decision making process (Gigerenzer \& Gaissmaier 2011).

Sloman (1996) suggests that in human mind, there are 2 systems that process information. The first system, namely the associative system, has a fast processing characteristic that mainly supports our natural life behavior to survive and such based on heuristics. The second system, namely the rulebased system, has a characteristic of a rational thinking that covers human behavior to learn and adapt. Another characteristic of rule-based system is this system requires more time and more effort to process because there is no heuristics available at the moment to speed up the process.

When applying professional judgment, internal auditor must combine those 2 systems proportionally to achieve a maximized output. In that process, associative system will play the role in generating a fast preliminary analysis and preliminary hypotheses based from experiences, then rule-based system will do the thorough analysis by employing another external factor and variable into the analysis so that the judgment will be more rational. The main problem when employing this kind of combination of both system is human, by its nature, uses the associative system to process general things in life automatically, but rule-based system must be activated intentionally to be employed inside human's mind (Sloman 1996).

In audit, the impact of heuristics, in which, causes bias will be impactful towards professional judgment in internal audit. Bazerman et al. (1997) said that the mistake in audit could happen because of the bias Published by Atlantis Press. 
inside auditor judgment. This kind of mistake within auditor professional judgment is the cause of failure within an audit.

In this aspect, researcher sees that there are some aspects causing internal auditors to fail in an internal audit engagement. Even though these kinds of phenomena happen often, this topic is rarely studied within scientific researches about auditing. This caused a force of attraction within researcher to study this interesting factor so that researcher could be credited inside this phenomenal research.

\section{THEORETICAL FRAMEWORK}

Inside the audit process, there is a stage namely fieldwork where the internal auditors collects data to make a report regarding how well is the company's internal control to protect its assets and such also to see if there's some fraud or misstatement within the company. The next stage is analyzing data that have been collected from those aspects and evaluating those data but, data's which underlying the analysis and evaluation must be a corresponding data's so that it will not cause an error in the analysis. In the documentation of the audit, there are several aspects to note. The first is the control of access to the documentation so that only persons with certain authority may access the documentation. Furthermore, it is also necessary to determine the need for storage retention so that storage does not depend on storage media because there are risks regarding the failure of storage media from the external or internal cause. In addition, a custodian policy is required to enable audit documentation to reduce the risk of information leakage. Lastly, IPPF also regulates the supervision of fieldwork. Supervision must be carried out based on the capabilities, experience of the internal auditor, and the complexity of the assignment.

In the introduction to the IPPF standard, it is mentioned that in conducting each stage of the internal audit, it is mentioned that the internal auditor should take the appropriate action using the auditor's professional judgment. According to Ancuta (2012), the application of professional judgment in the audit begins when one applies the experience, knowledge, and abilities that have been obtained so far with the limitation of the activity that limits the perspective of the approach so that there is no different perception of the case at hand. According to Boureanu (2006), steps in making professional judgment are identify an define the problem; gathering facts, information, and identifying relevant literature; conduct analysis and identify alternatives; documenting and reviewing all information gathered and steps performed; and make decision. In addition,
Grout et al. (1994) defines professional judgment as a condition for making decisions by considering several important factors. These important factors include the inherent risks of the firm, the risk of internal control, the detection risk present within the auditor itself and other factors. With this, the professional judgment made throughout the audit includes consideration of the above factors so that it should make auditors more cautious in making professional judgments.

The definition of social cognition by Greenberg (2015) is a way an individual to understand their own social world. According to Baron et al. (2012), social cognition is divided into several aspects, namely: schema, associative \& rule-based system, heuristic \& bias, magical thinking, and affect. In these five aspects, it is an integral part of the human decision processing line which can be described as follows.

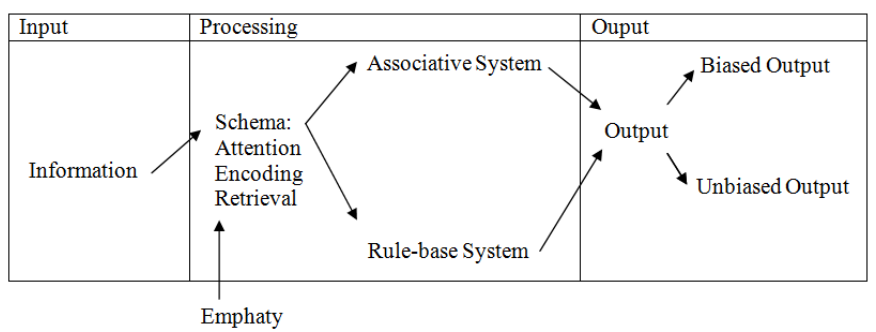

Figure 1. Social cognition chart. source: Baron et al. (2012) data processed

Schema or mental framework is a template of our thinking that is shaped based on our experience, education, environment, and social interaction during our lifetime. Given this schema, we can understand some patters of activity such as understanding what is ethical and what is not, what to do after we do an action, and so forth. Schema influences our social thinking through 3 stages which are attention: what information we see; encoding: the process of recording information in memory; retrieval : the process of retrieving information from memory to use.

This schema will be used as a processing base in both automatic and controlled thinking Shuman (2010) states that empathy can cause a person to frame the data acquisition process. This framing aspect can occur in the process of attention so that unconsciously someone will pay more attention to information that falls into the person frame of beliefs than the information that is outside the frame. In addition, the framing process will be a filter of information in the retrieval process so that the retrieved data fall in accordance with the frame. 


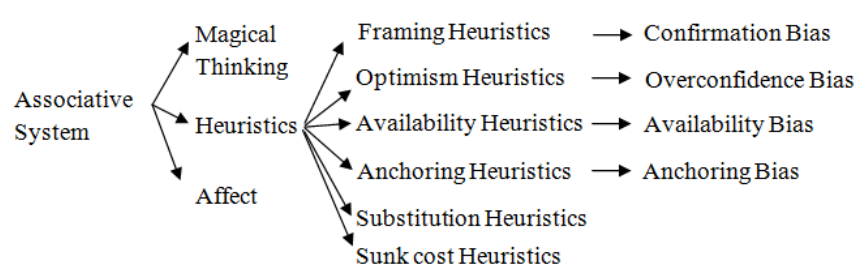

Figure 2. Associative system chart. source: Kahneman (2011) data proceed.

After the data are taken, the data will be processed in mind through 2 thinking system which are associative system, which is fast and operates automatically, and rule-based system, which is slow but operates rationally. In the associative system, there is a heuristic which is a shortcut of thought that will simplify the thinking inside one's mind, magical thinking which is the thinking about things that are beyond normal reasoning like spiritual things, and affection which is a thought of one's feelings. The next stage is the merging of these two systems of thought processes to make a ideal thinking which associative system plays the role of making a base preliminary opinion from experiences whereas rulebased system takes control to think further into the matter based on the preliminary opinion formed by employing other factors outside the matter to produce an ideal decision.

The output resulting from incorporating those processing systems divided into 2 results. The first is the biased output which the output contains a bias due to certain factors and the unbiased output which has no bias contained. The Bias itself has many types based on the causes \& effects. In this study, researchers chose only 4 of them according to AICPA guide regarding auditing which states that in audit there are 4 types of bias.

Confirmation bias is bias occurs when a person gives a higher percentage of value to information that supports his initial belief in something. Rabbin \& Schrag (1999) suggests that one example of confirmation bias is about first impression. The informative first impression will make a person convinced about what he believes toward the subject and will unconsciously tend to make a defensive reaction to the opposite opinion.

Availability bias is bias occurs when there is a tendency from the auditor to consider heavily in information which is available in mind rather than seeking fully valid information. In discussing the availability bias, there is a concept in availability heuristic called ease of retrieval (Kahneman 2011). This term describes the thinking of people having a tendency to use data that are easily retrieved from memory such as data that have recently occurred, data that have a meaningful value to the user, the data available at that time, etc.

Overconfidence bias is the result of a thinking process using optimism heuristic. According to Sweeny \& Shepperd (2009) optimism heuristic, is a state of mind which has a contingency to think optimistically. There is one characteristic of optimism heuristics that makes one's mind vulnerable to overconfidence bias and that is planning fallacy. Planning fallacy is a condition when one's planning becomes useless because of several factors that an optimist mind can't foresee (e.g. predicting sales of a brand new product without considering competitor's point of view). Disregarding those factor means that there are some limitations inside one's mind that unconsciously filter those information.

Anchoring Bias takes action when in some condition; an unprepared mind has a contingency to think based on the first information given to them. Kahneman (2011) illustrates this bias as when someone is doing a negotiation. When negotiating a tender, the proposing party can bid any price they want according to their business plan, but the first bid plays a crucial role because it can anchor the accepting party about the fair price about the project. If a subsequent bid has a big difference toward the initial bid, the accepting party will wonder about why it is so expensive, whether it includes any new benefits, why it is too cheap, whether it has a poor quality.

\section{RESEARCH METHODS}

Data collection methods used in the study was document analysis, semi-structural interview, questionnaire, and observation. Document analysis was done by digging information regarding the implementation of internal audit inside the company so that researchers understand the internal audit stage conducted inside the company. A semi-structured interview method was done. Interviews were conducted with the audit team manager, audit team manager in the past (director), audit team member, and an employee to acquire any information which the audit team did not reveal. The questionnaire used was a questionnaire which was invented by Baron et al. (2012) about the EQ (Empathy Quotient) test to determine the level of empathy of a person and relate it to confirmation bias to confirm Shuman's (2010) theories regarding empathy and confirmation bias. The participatory observation was conducted within 3 months i.e. in December 2013, 2014, and 2015 in "Company X" to see the actual events that occurred so that researcher can relate the observation to other data acquired. 


\section{RESULTS AND DISCUSSION}

In company $X$, internal audits are carried out using only some of the basic aspects of internal audit such as field observation, materiality assessment, and analytical procedures. This indicates when conducting internal audit, company $\mathrm{X}$ is still unable to perform all aspect of internal audit as regulated in IPPF due to lack of knowledge of the management and audit team regarding the standards also regarding good internal audit activities. In addition, the company noticed that some aspects of the audit cannot be applied because it is not possible to do for some reasons such as the inability of the auditor to comprehend what IPPF regulates.

The researcher's findings prove that in the signal detection theory, in receiving a signal, one can make a response that doesn't match with what it really is. The internal noise that exists in the case of company $\mathrm{X}$ is a noise in the form of a person's unconsciousness of heuristic that is running in his mind. These variables will cause a distortion in the form of bias that causes a deviation from the actual reality so that information processing produces an output that is less appropriate to solve the problem.

Confirmation bias will cause information received by a person automatically filtered by a "frame". This makes the signal that a person receives becomes insufficient to make a proper opinion objectively but supports one's beliefs or opinion. In company $\mathrm{X}$, the former person in charge of internal audit (the company director) always thought that the audit procedures that he employed were the best for the company because the other said so. The company directors unconsciously took account only the supporting sides but disregard the opposing sides of the opinion so that his opinion could be testified as good.

Anchoring bias will cause a person to process the information that is available as his mind but based on others. Based on that signal, one will make a judgment and employ a few adjustments from the base information. This kind of bias will make the receiving party unknowingly apply an anchor inside his mind without confirming whether the information is manipulated or not. In company $\mathrm{X}$, the director happens to make a decision regarding the materiality in the audit based by other company materiality within an organization named "Hiswana", an organization for the owners of fuel distribution company, without considering any other factor such as the difference between company size, company internal controls, etc.

Availability bias will cause a person to only process information from visible and retrievable signal only from the memory at the moment. This charac- teristic will make a person mind be limited into that data, so the response will be generated from a limited data which will cause a less appropriate reaction towards the problem at that moment. At company X, the person in charge of the audit, the audit manager, always stated the same example when asked about a different question about the failure of the internal control within the company. However, even if the audit manager happened to have a sign of being affected by availability bias, the procedure when implementing the audit makes the probability of this bias to take form is minimal. This was proved by the note of the auditor about the discussion that took place within every audit. By engaging a discussion, the audit team will mitigate the occurrence of availability bias because it will provide the audit team member an insight about other perspectives which in turn will make judgment from an informative pile of data.

Overconfidence bias will cause a person to pay less attention to the existing signal seriously so in conjunction, it will make the person less ready to respond in an appropriate way. This lead to a failure in conducting an audit activity due to lack of prepared planning. Within "Company X", planning failures have never occurred significantly but there is an overconfidence bias inside the audit team leader's mind.

\section{CONCLUSSION}

The authors conclude that the four biases in internal audit are only some of the many factors of failure in the internal audit which will disrupt internal auditor's professional judgment from the beginning of audit activity. In addition, there is also a linkage that supports the Signal Detection Theory which said that the signals put forward in the theory will be processed in the human's mind and the noise, as raised in the theory, is the illustration of biases which affects one's mind. This study proves that the bias makes a signal which will disrupt one's responses to the signal received causing the response to be less appropriate.

\section{REFERENCES}

Baron, R.A. 2012. Social Psychology Thirteenth Edition. New Jersey: Pearson.

Bazerman, M.H., Morgan, K.P., \& Loewenstein, G.F. 1997. The impossibility of auditor independence. Sloan Management Review 38(4): 89 -94.

Boureanu, M. 2006. Rationamentul profesional in investigatiaauditorului. Tribuna Economica Review 45: 23.

Fiske, S.T. \& Taylor, S.E. 2008. Social cognition: from 
brains to culture. New York: McGraw-Hill.

Gigerenzer, G. \& Gaissmaier, W. 2011. Annual Rev. Psychol 62:451-82.

Greenberg, J. 2015. Social Psychology the science of everyday life. New York: Worth Publishers.

Grout, P., Jewitt, I., Pong, C., Whittington,G., Dewatripont, M., \& Laroque, G. 1994. Auditor`s professional judgement:implications for regulation and the law. Economic Policy 9 (19): 307-351.

Kahneman, D. 2011. Thinking fast and slow. US: Strauss and Giroux.

Rabin, M. \& Scharg, J. 1999. First impressions matter: A model of confirmatory bias. The Quarterly Journal of Economics 114(1): 37-82.

Shuman, D.W. \& John A.Z. 2010. Empathy or objectivity : the forensic examiner's dilemma?. Behavioral Sciences and the Law 28: 585-602.

Sloman. 1996. The empirical case for two systems of reasoning. Psychological Bulletin 119(1): 3-22.

Sweeny, K \& Shepperd, J. 2009. Responding to negative health events: A test of the Bad News Response Model. Psychology and Health 24(8): 895-907. 